\title{
Prognostics and Health Management of Wind Turbines: Current Status and Future Opportunities
}

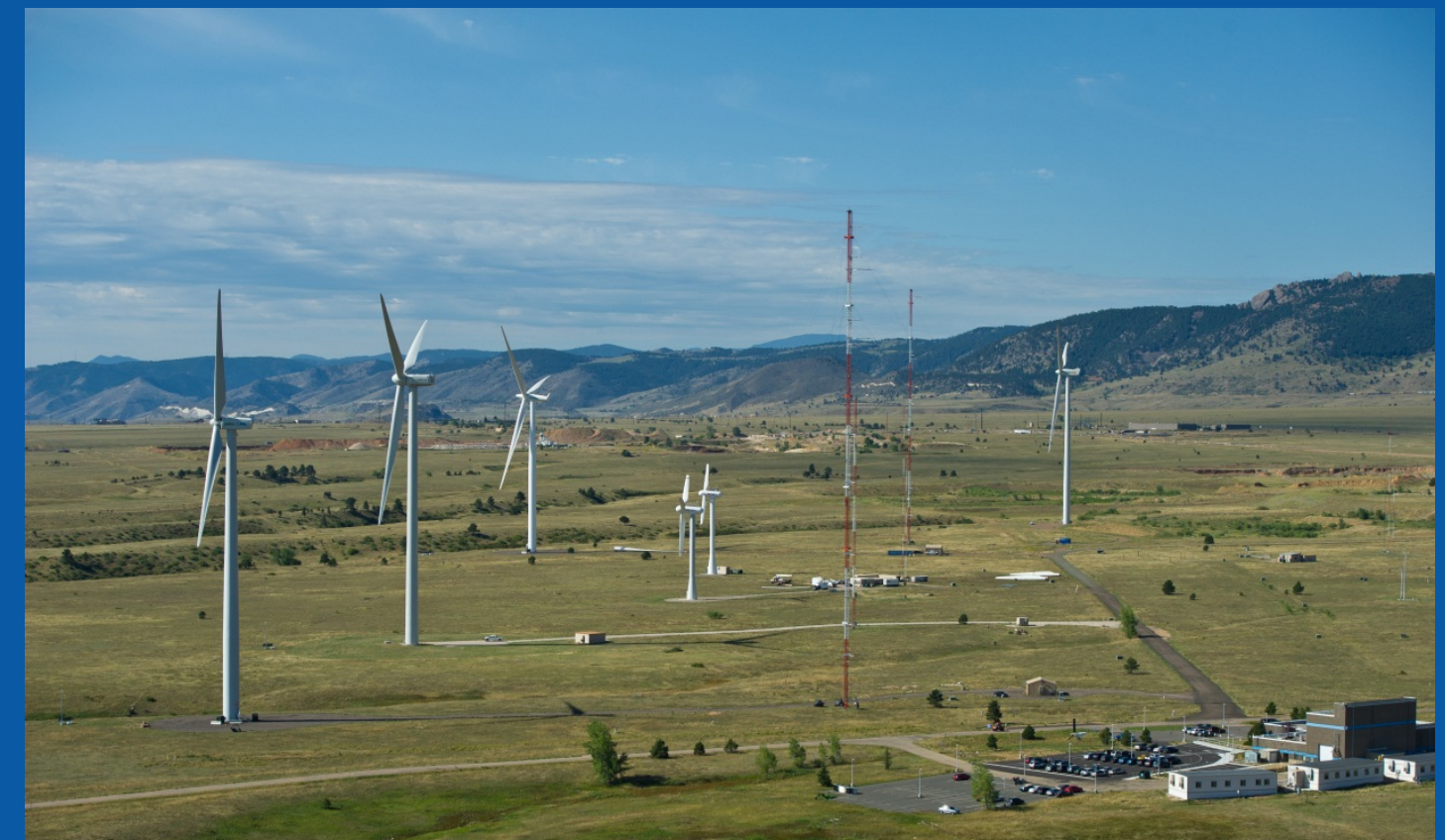

Photo by Dennis Schroeder, NREL $21883=$ a $^{2}$
Shuangwen (Shawn) Sheng National Renewable Energy Laboratory (NREL), U.S.A.

Probabilistic Prognostics and Health Management of Energy Systems Workshop

December 14-15, 2015

Ilha Solteira, SP, Brazil 


\section{Outline}

- Introduction

- Current Status of Prognostics and Health Management in Wind Industry

- Research and Development (R\&D) Activities

- Concluding Remarks 


\section{Introduction}

- Global Wind Energy

- Wind Turbine Reliability Challenge

- Wind Plant Operation and Maintenance (O\&M)

- Prognostics and Health Management
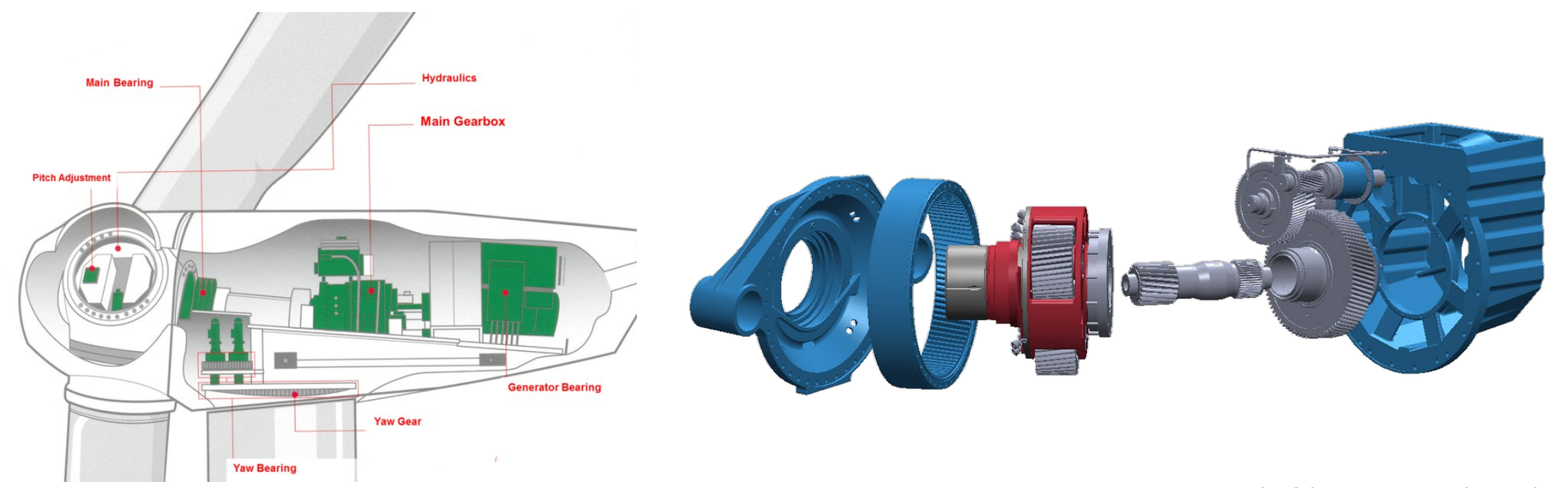

Illustration Credit: Jon Leather, Castrol (left) and NREL (right) 


\section{Global Wind Energy}

\section{GLOBAL CUMULATIVE INSTALLED WIND CAPACITY 1997-2014}

400,000 MW

350,000
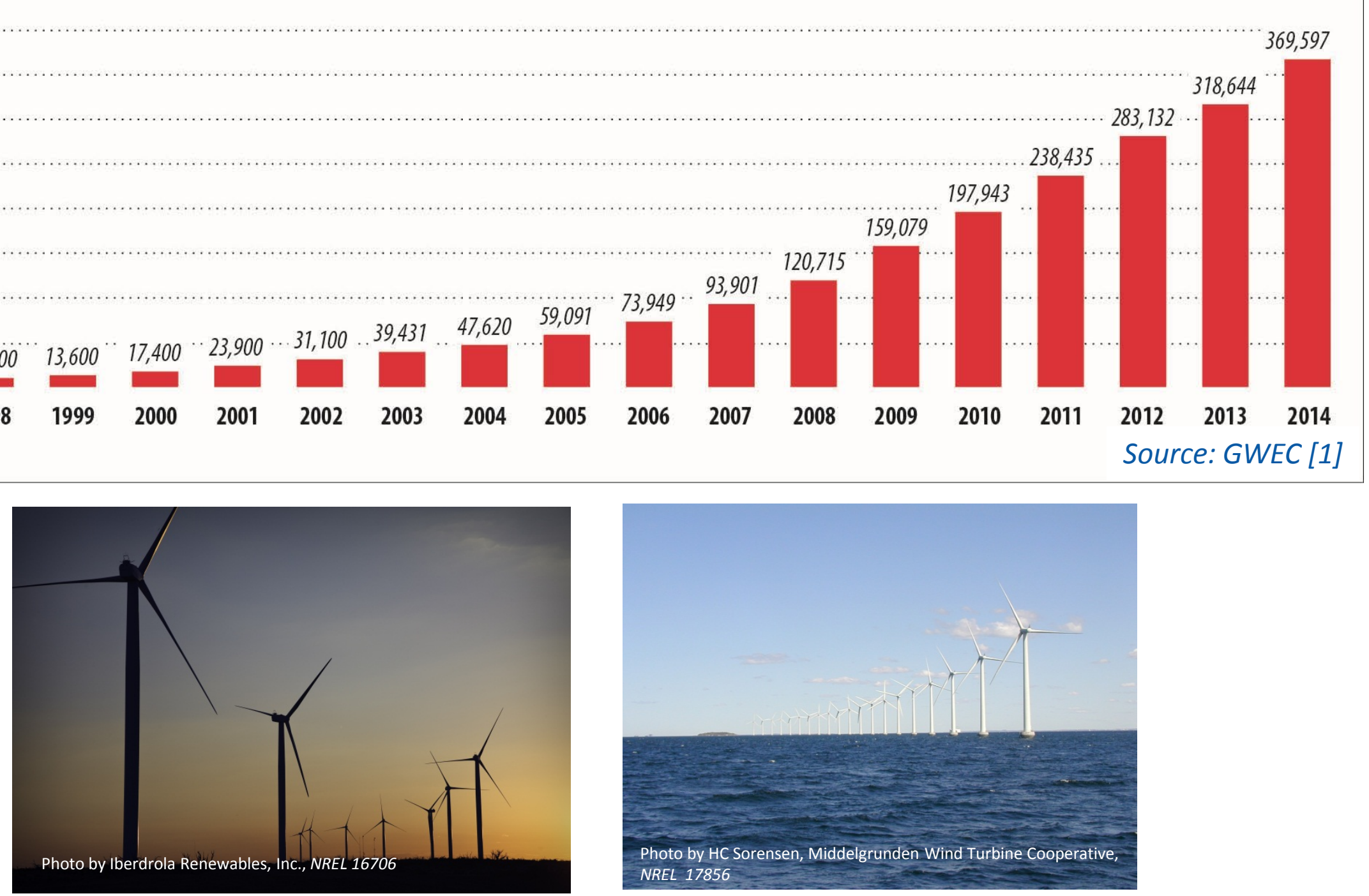


\section{Reliability of Turbine Subassemblies: Old Statistics $[2,3]$}

\section{Failure/turbine/year and downtime from two large surveys of land-based European wind turbines over 13 years}

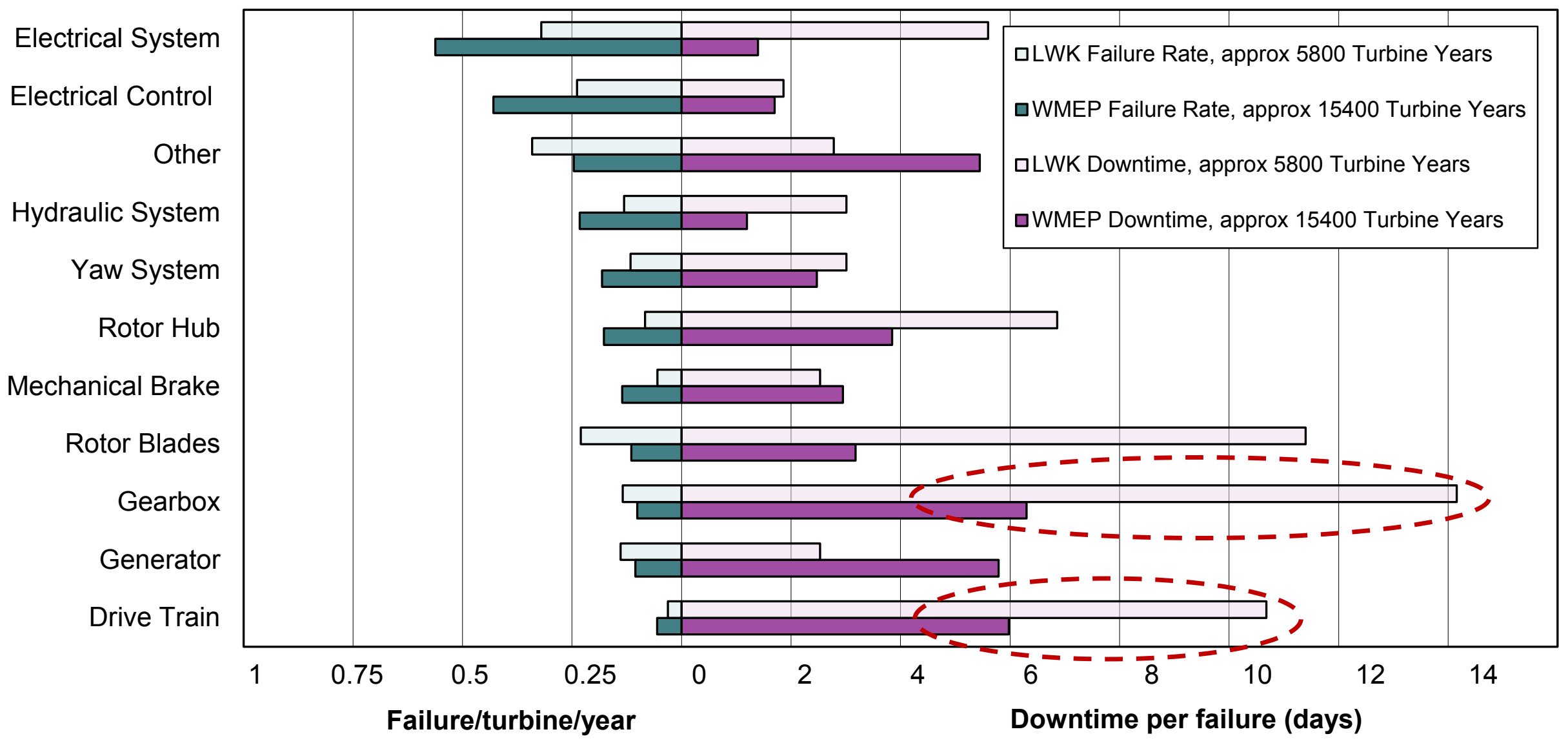

- The Wissenschaftliches Mess-und Evaluierungsprogramm (WMEP) database was accomplished from 1989 to 2006 and contains failure statistics from 1,500 wind turbines.

- Failure statistics published by Landwirtschaftskammer Schleswig-Holstein (LWK) from 1993 to 2006 contain failure data from more than 650 wind turbines. 


\section{Outage Duration for Different Subsystems: New Statistics [4]}

- Downtime caused by premature component/subsystem failures, led by gearboxes, challenging the wind industry and resulting in increased cost of energy for wind power

Average Turbine Outage Duration

for Failures $>1$ Hour (days)

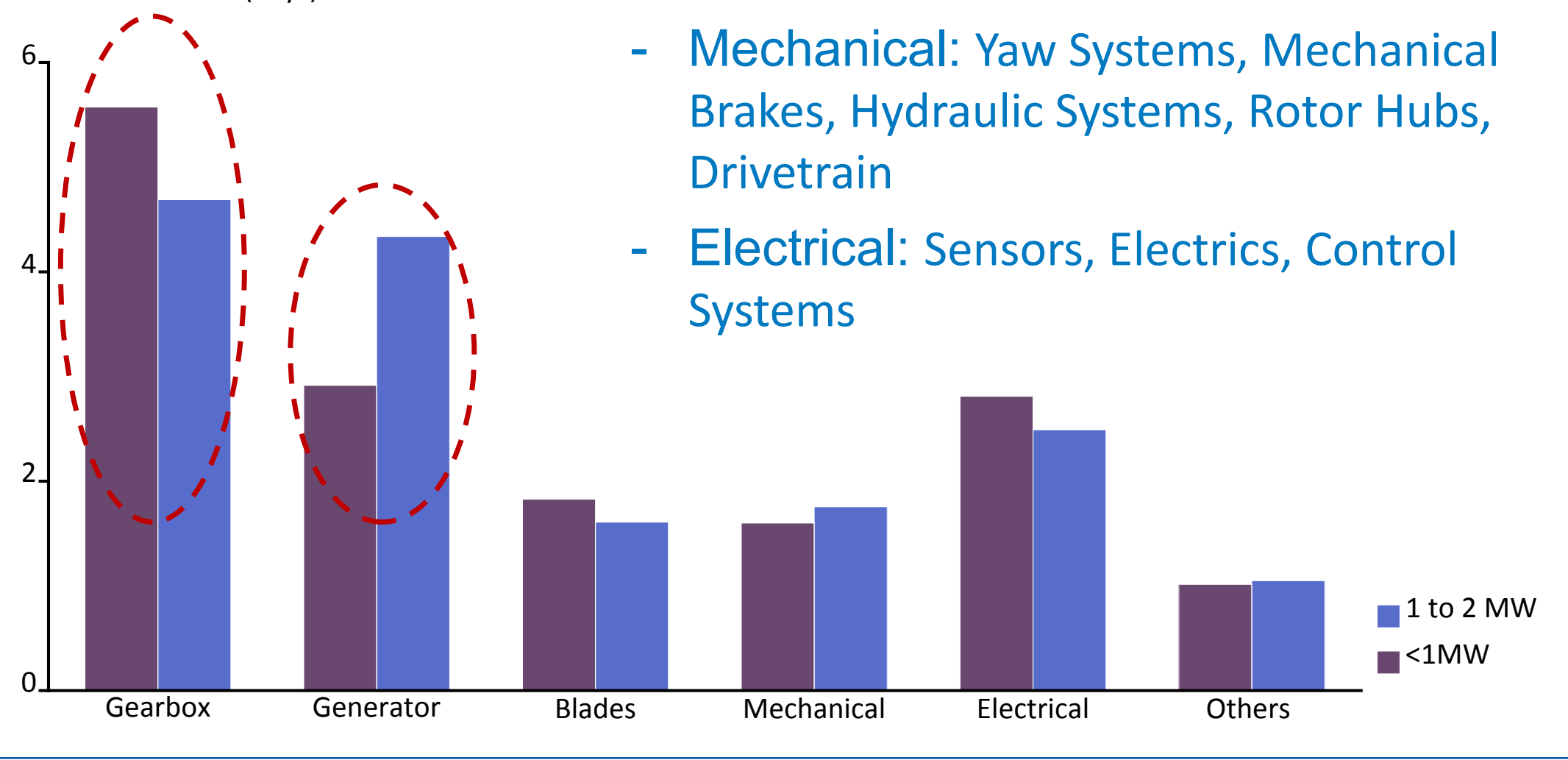




\section{Wind Plant O\&M}

- O\&M research needs:

- The majority of the wind turbines ( 370 gigawatts [GW]) installed worldwide are out of warranty

- A $1 \%$ performance improvement: $\$ 1.2$ billion additional revenue (assumed: $30 \%$ capacity factor, $\$ 120 /$ megawatt-hour [MWh] electricity rate)

- Extremely high replacement costs for most subsystems [5].
- O\&M cost reduction and business opportunities:

- $\quad 21 \%$ of life cycle cost for offshore plants and $11 \%$ for land-based plants [6]

- Further reductions achievable by improved O\&M practices

- Global O\&M market likely to reach $\$ 20.6$ billion by 2023. [7]

- Actions to improve performance, reliability, and availability more critical for offshore wind. 


\section{Prognostics and Health Management}

- One definition of prognostics and health management [8]: an approach to system life-cycle support that seeks to reduce or eliminate inspections and time-based maintenance through accurate monitoring, incipient fault detection, and prediction of impending faults.

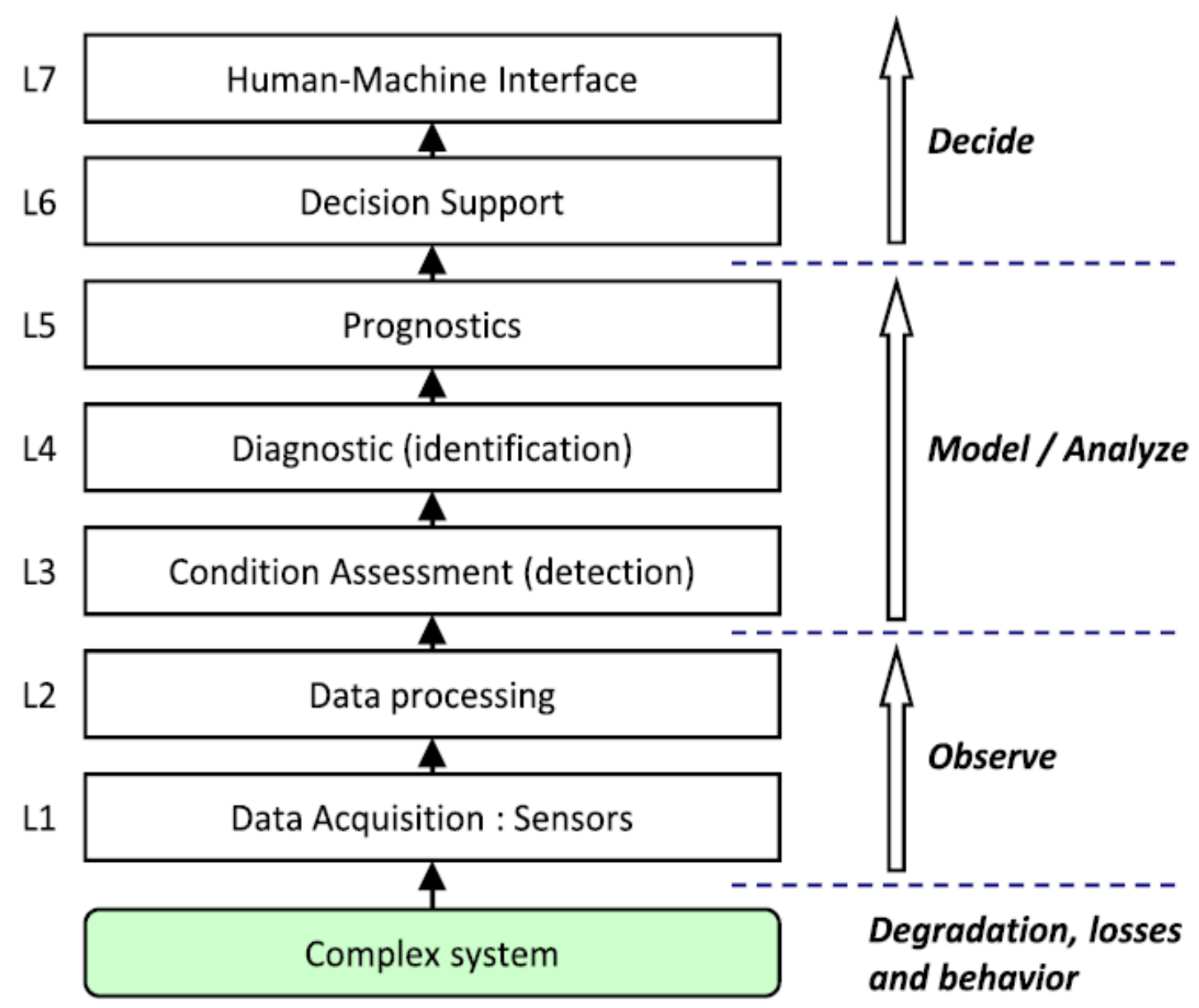

One Architecture for Prognostics and Health Management Process [9] 


\section{Prognostics and Health Management (Cont.)}

- Benefits [10]:

- Increased productivity

- Reduced downtime

- Reduced number and severity of failures, particularly unanticipated failures

- Optimized operating performance

- Extended operating periods between maintenance
- Reduced unnecessary planned maintenance

- Reduced life-cycle cost.

- Applications:

- Fuel cell systems

- Nuclear power plants

- Aviation

- Electronics

- Wind. 
- Focuses

- Typical Practices

- Performance Monitoring

- Condition Monitoring.

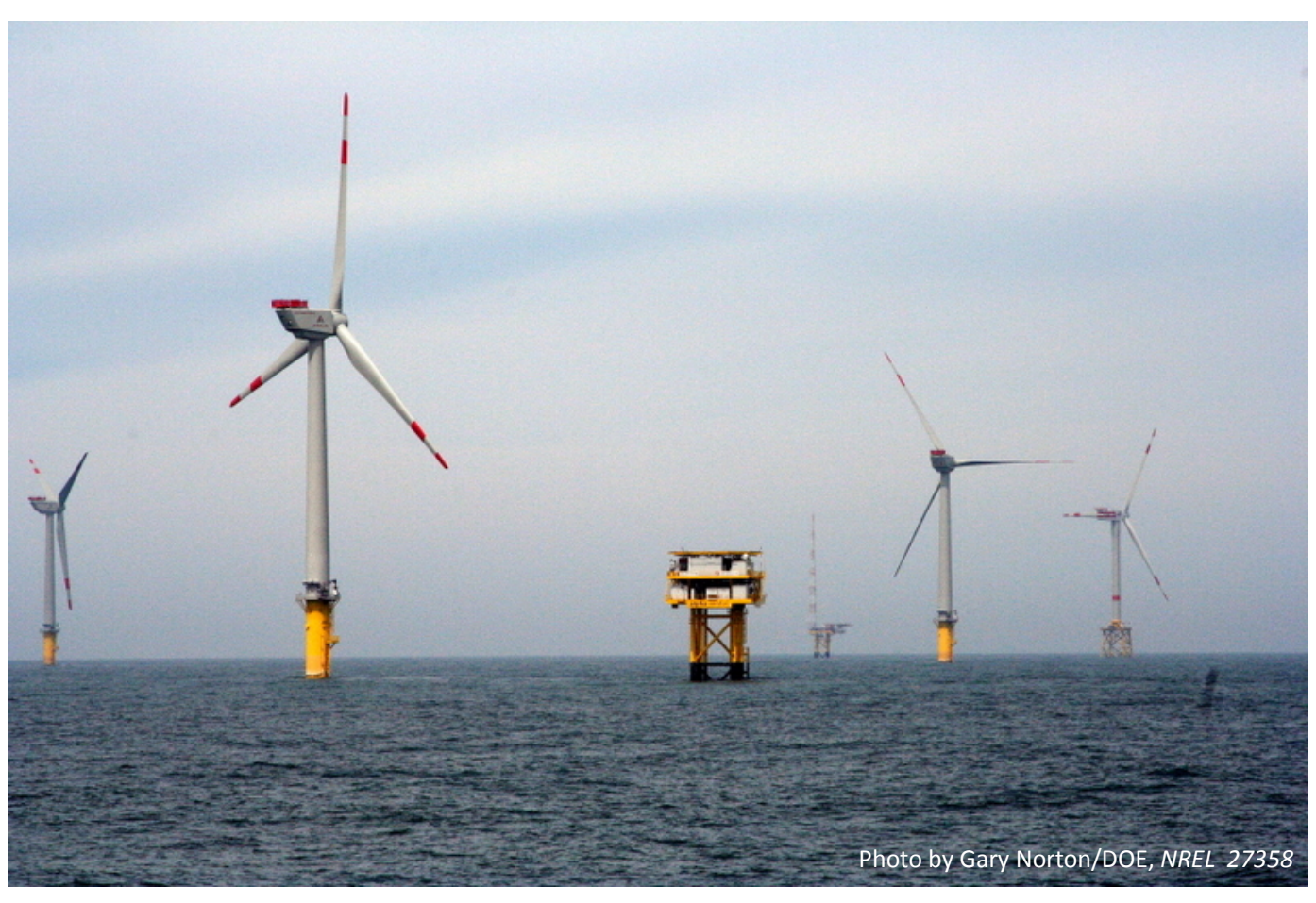




\section{Focuses}

- Subsystems on drivetrain: main shaft bearing, gearbox, and generator

- Layers 1 to 4: sensing, signal processing, fault detection, and diagnostics

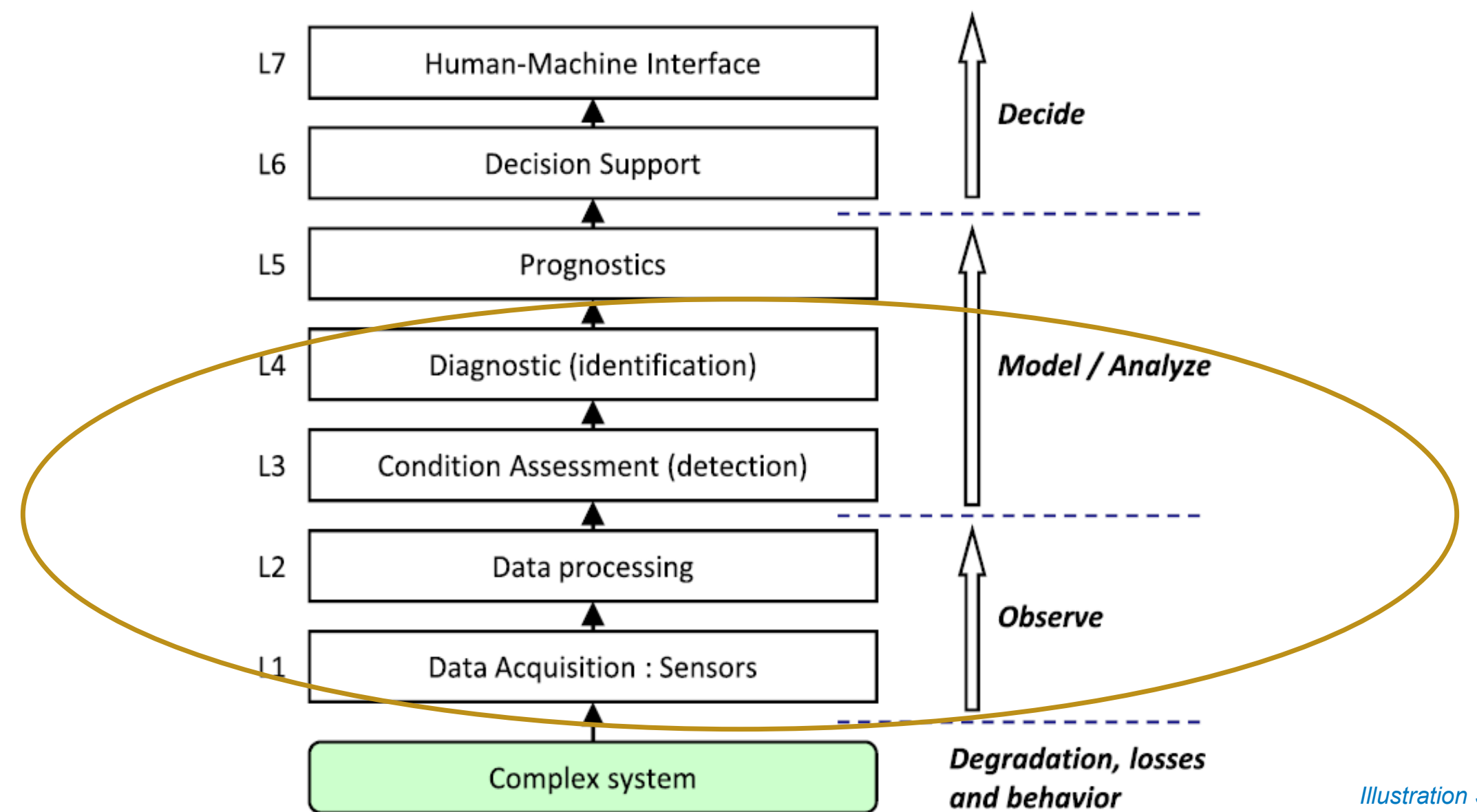

and behavior

Illustration Source: [9] 


\section{Performance Monitoring Using SCADA Data}

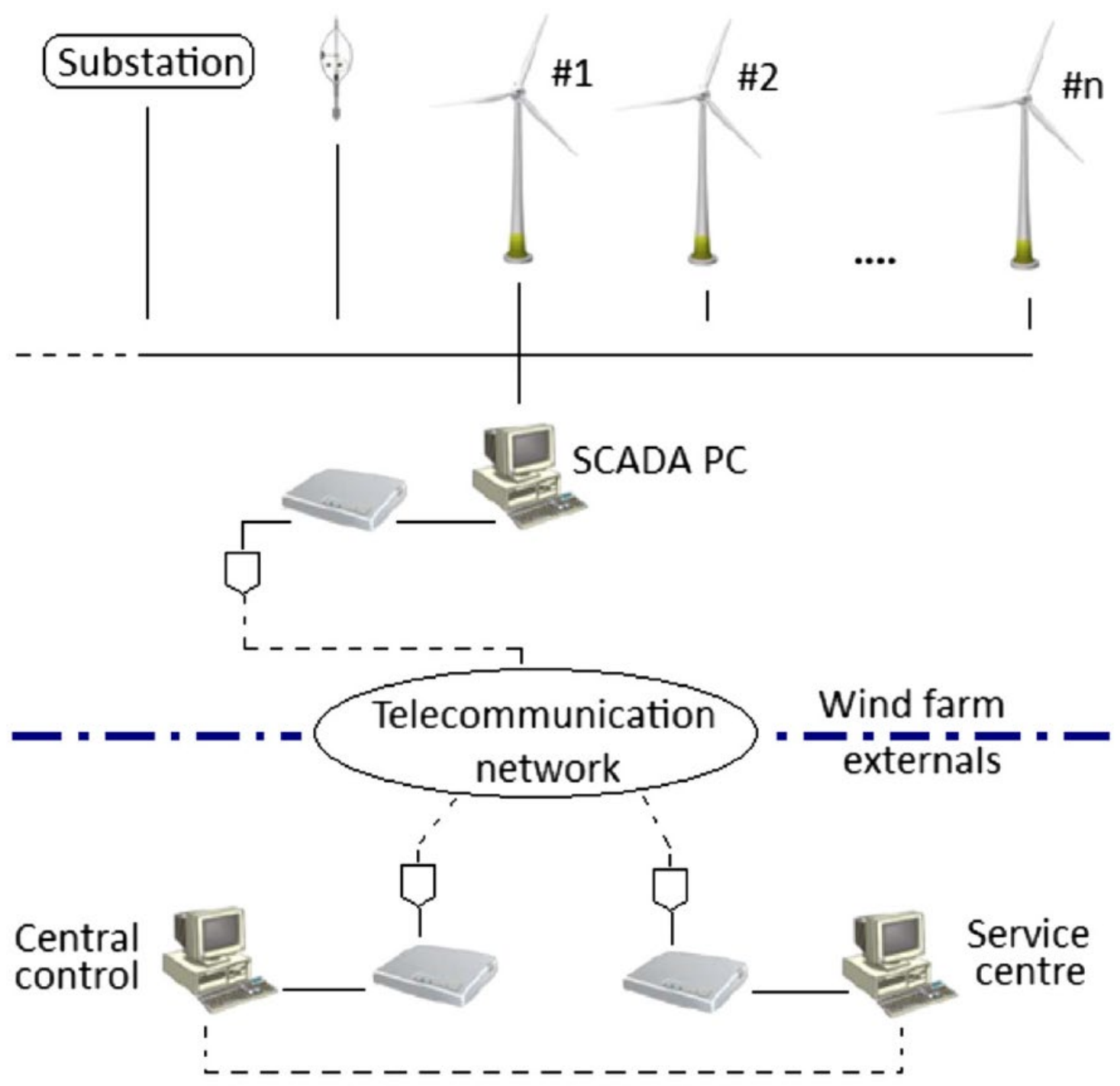

SCADA: Supervisory Control and Data Acquisition 


\section{Performance Monitoring}

- Classification of Measured Parameters [11]:

- Wind parameters: e.g., speed, deviation

- Performance parameters: e.g., power output, rotor speed, blade pitch angle

- Vibration parameters: e.g., tower acceleration, drivetrain acceleration

- Temperature parameters: e.g., bearing and gearbox temperature.

- Grouping of Control System Status Report [12]:

- Status codes: e.g., error, warning

- Operating states: e.g., brake, start, yaw, pitch.

- Analysis:

- Correlate different groups of parameters (e.g., power and wind), develop models for normal operational states, and use these models to identify abnormal scenarios

- Conduct statistical analysis of events (e.g., status codes) experienced by turbines at a wind plant. 


\section{Performance Monitoring $[5,14]$}

- Benefits:

- Readily available and no need of investment in dedicated condition monitoring instrumentation

- Helpful for identifying outliers that may need further inspection by looking at key performance parameters or status codes.

- Drawbacks:

- May not be straightforward in pinpointing exact damaged subsystems/components (e.g., bearings or gears inside gearboxes)

- Many false alarms caused by varying loads experienced by turbines

- Does not meet full turbine condition monitoring needs, such as fault diagnosis. 


\section{Example: Main Shaft Bearing [15]}

Actual $\longrightarrow$ Estimate $\longrightarrow$ Alert $X \quad$ Incident $\diamond$

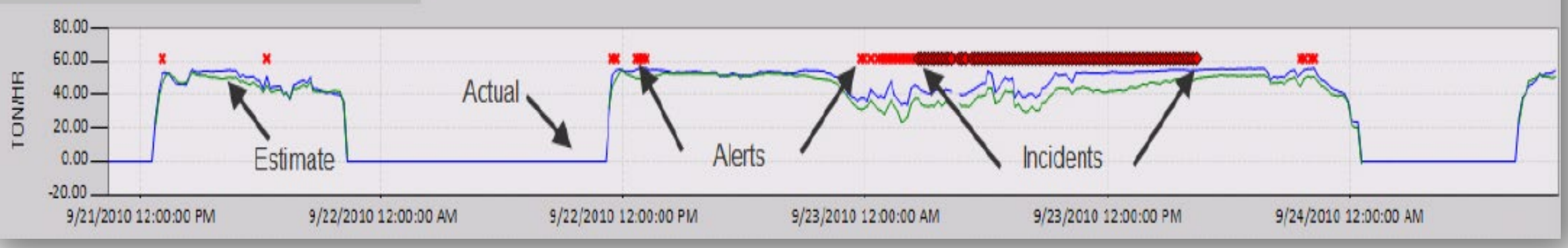

Main Shaft Bearing

Fault

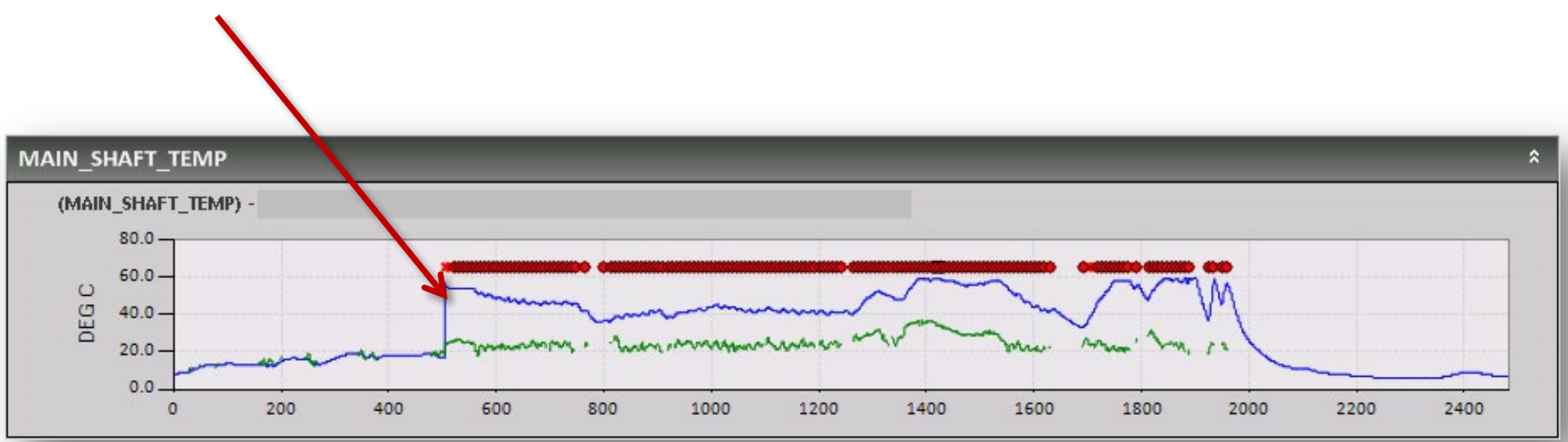




\section{Condition Monitoring $[5,13]$}

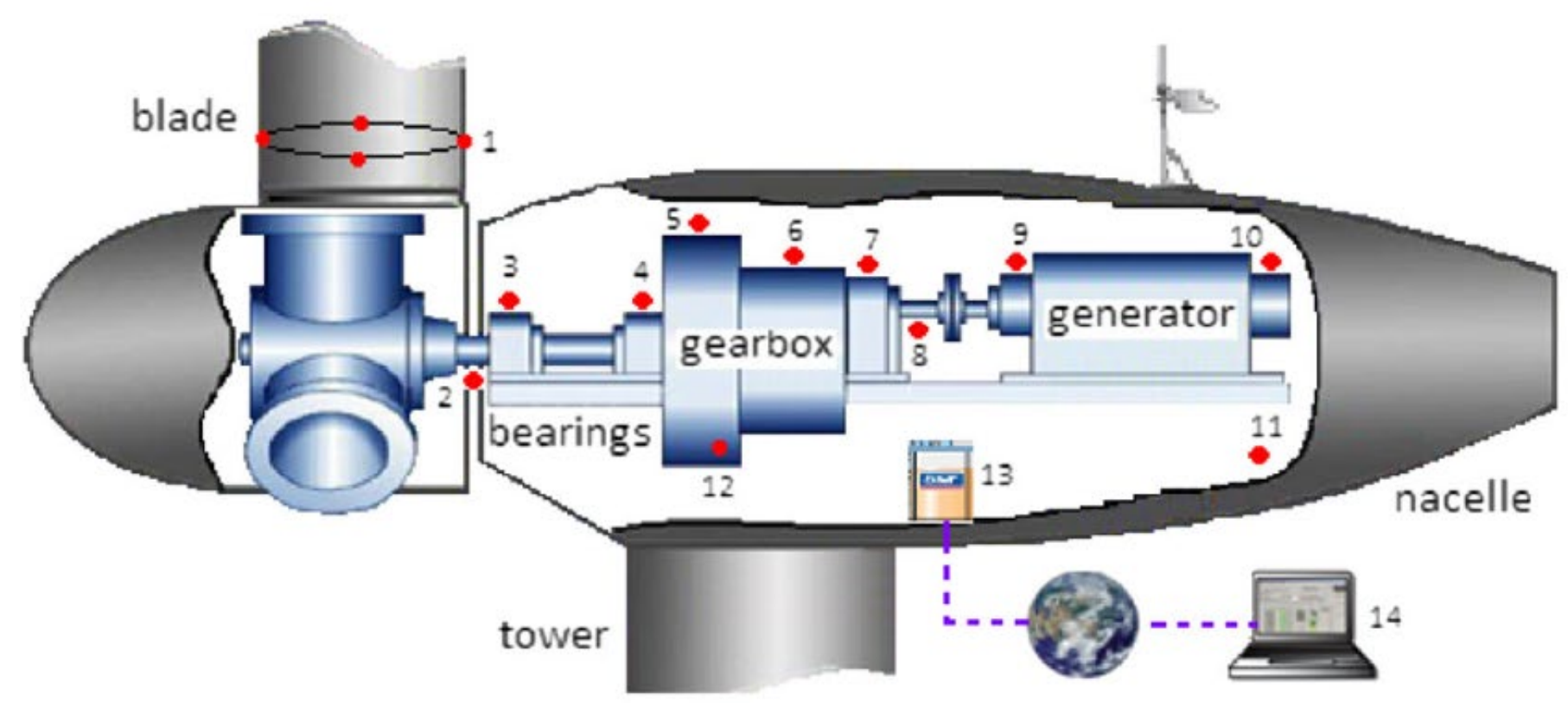

1 -..- fibre optic transducers; 2,8 -.- speed transducers; $3,4,5,6,7,9,10,11$-.. accelerometers; 12 -.- oil debris counter; 13 ..- online CMS; 14 ... PC at control center.

- Typical Techniques:

- Acoustic emission (e.g., stress wave) or vibration analysis

- Oil.
- Real-time continuous or offline periodic

- One or a combination of a few. 


\section{Condition Monitoring with the Drivetrain as a Focus}

- Raw Signal Examples:

- Accelerations, acoustic emissions

- Oil debris counts, oil cleanliness measurements.

- Feature (Condition Indicator) Examples:

- Preprocessing: filtering

- Time-domain statistical parameters: peak, root mean square

- Frequency domain: gear meshing frequencies and sidebands, bearing fault frequencies, and their statistical values.

- Typical Diagnosis:

- Trending or rate of changes of features or condition indicators

- Appearance of frequency components corresponding to certain faults or abnormal modulation of signal spectra

- Violating thresholds set for certain features. 


\section{Condition Monitoring}

- Benefits:

- Capturing high-frequency dynamics normally not achievable with a typical SCADA system

- Identifying more failure modes occurred to turbine subsystems or components

- Pinpointing exact damaged locations/components

- Enabling condition or reliability-based maintenance, prognostics, and health management.

- Drawbacks:

- Additional investment required for instrumentation and monitoring service

- Dedicated resources on data analysis and interpreting results. 


\section{Gearboxes: Vibration Analysis [16]}

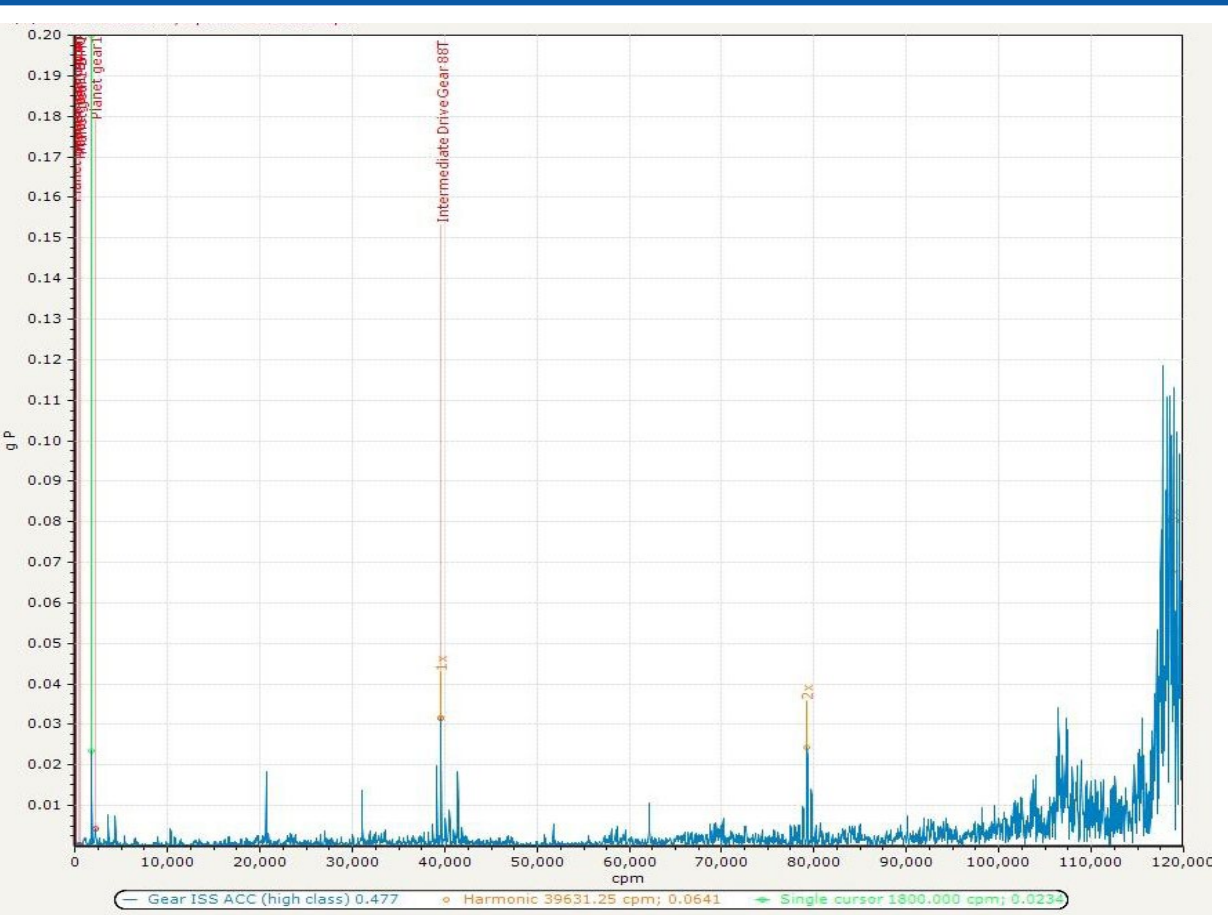

- Dynamometer retest of the damaged gearbox (right) indicated abnormal behavior

- More side band frequencies

- Elevated gear-meshing frequency amplitudes.
- Intermediate-speed-shaft sensor

- Dynamometer test of the healthy test gearbox (left) indicated normal gearbox behavior.

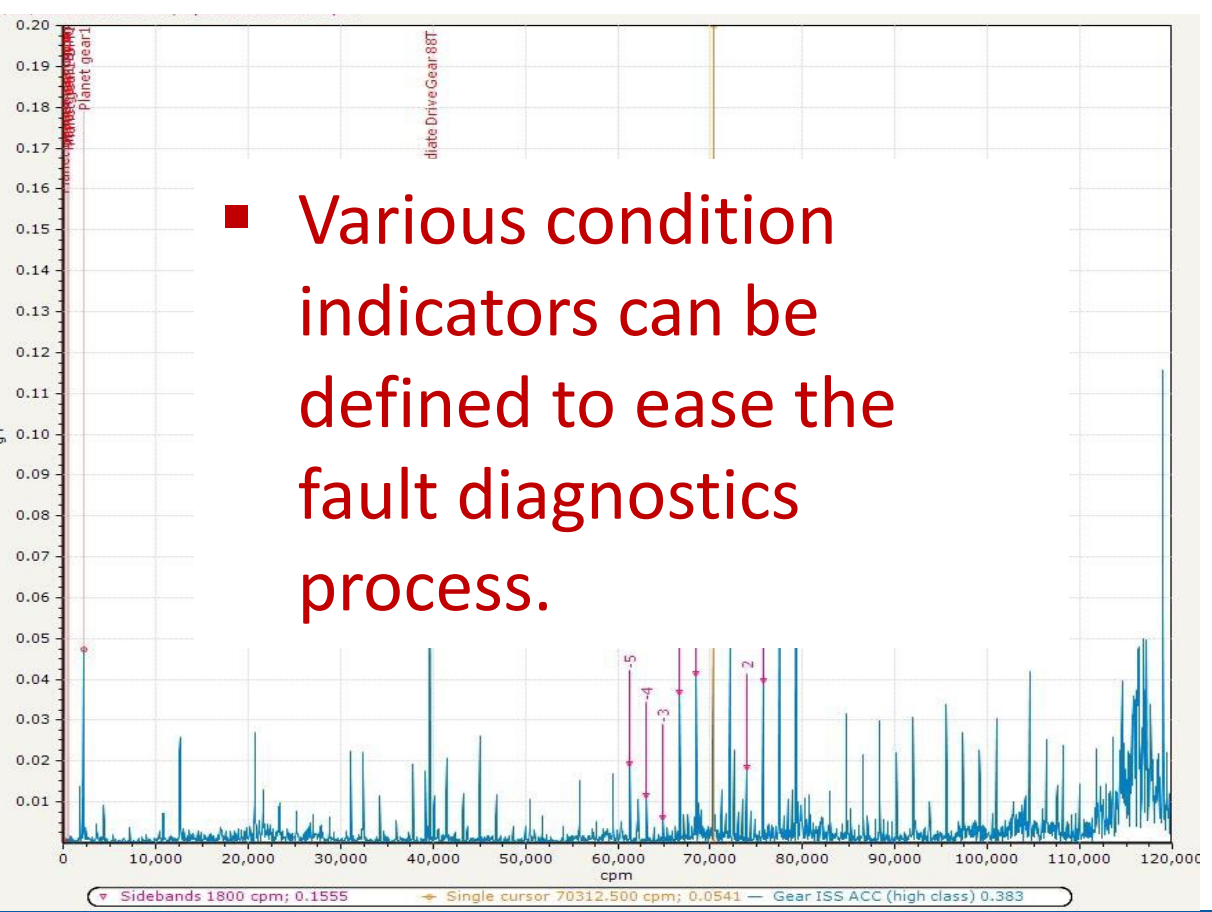




\section{Test Gearbox Lubrication Diagram [17]}

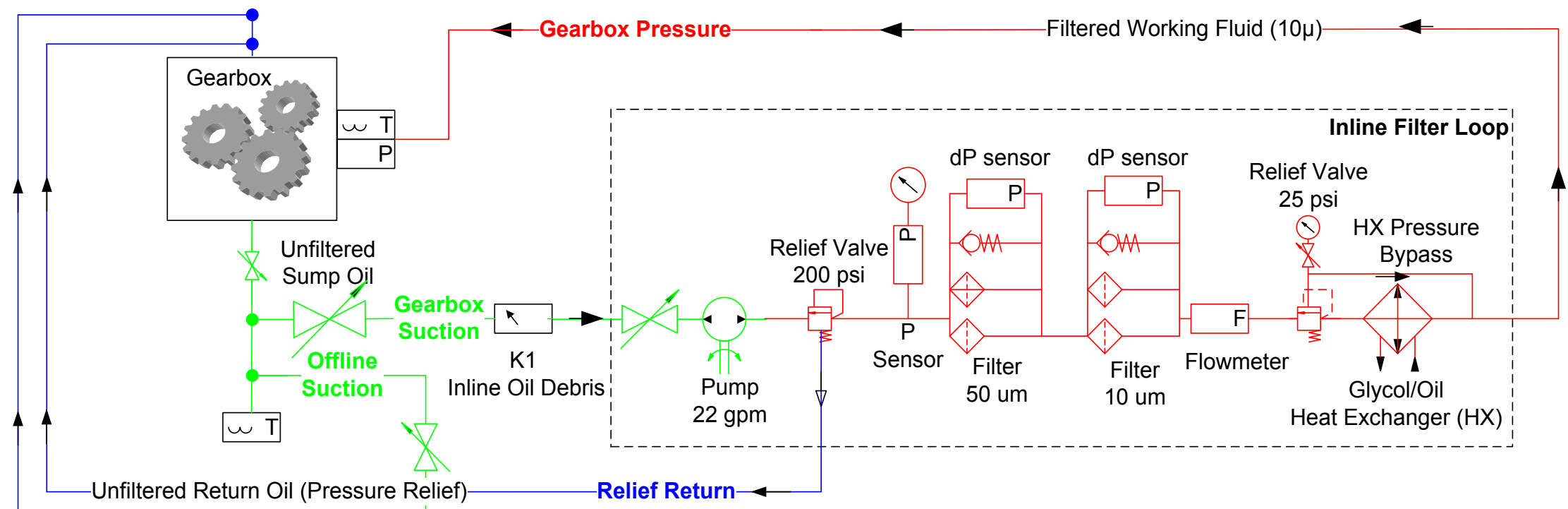

Kidney Loop Return

Filtered $(3 \mu, 0.24 G P M)+$ Unfiltered (0.026GPM)-

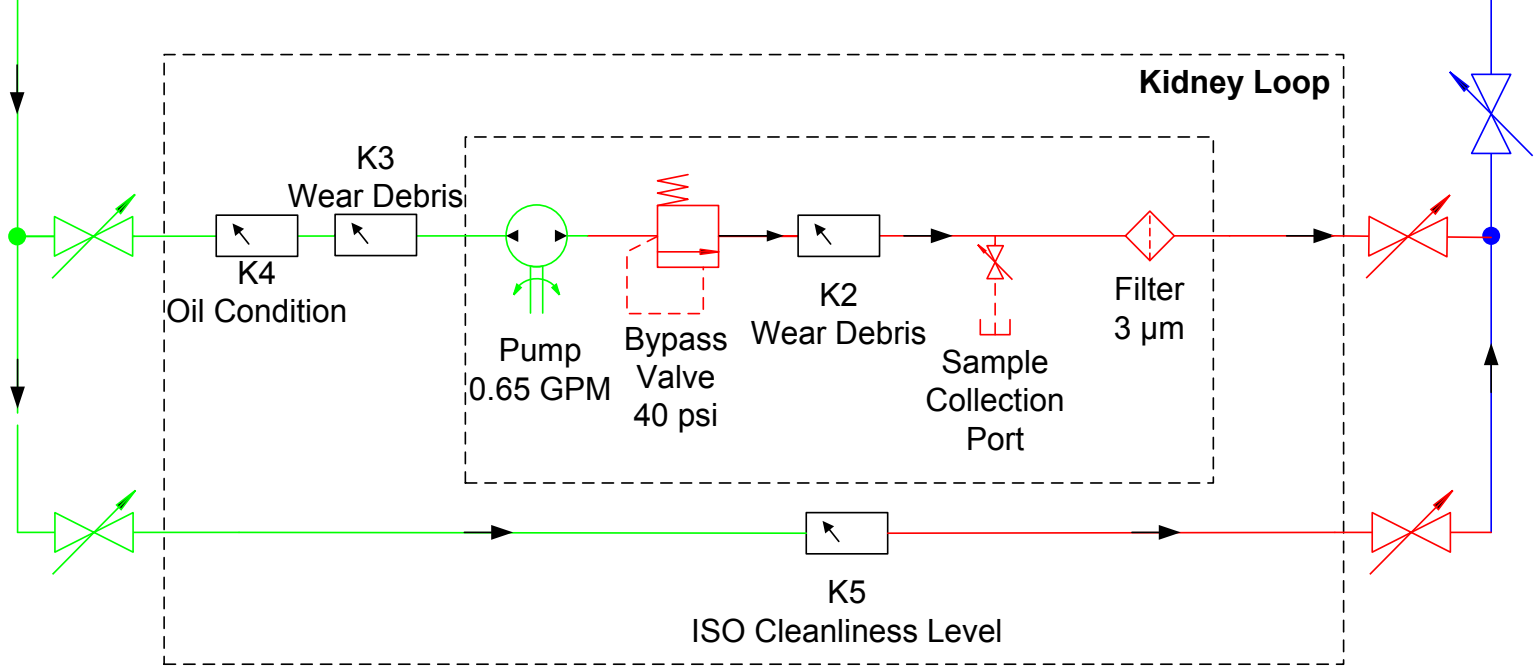




\section{Gearbox: Oil Debris Monitoring by K1 [17]}

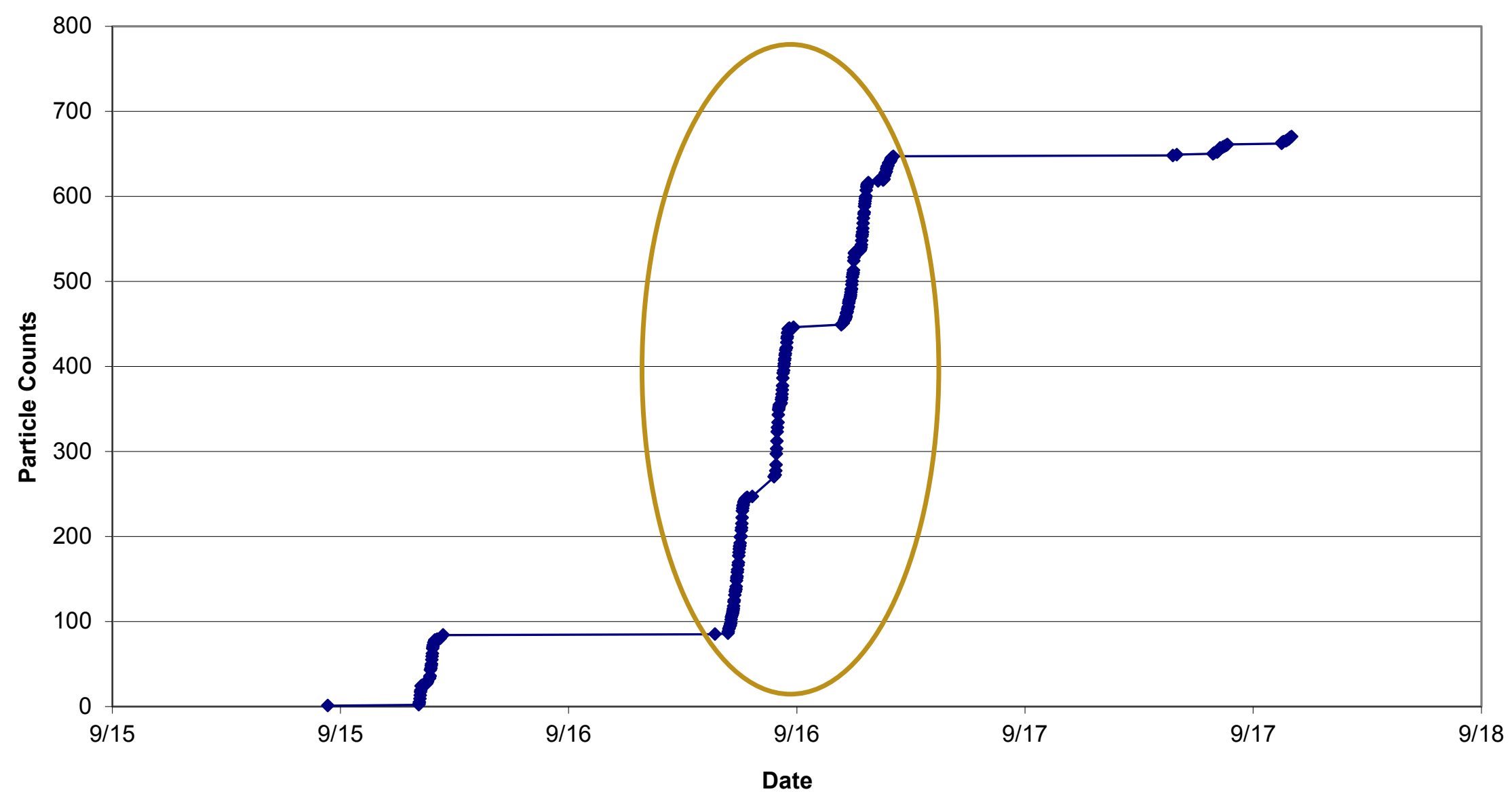

- Particle generation rates:

- Damaged test gearbox: 70 particles/hour on 9/16/2010

- Healthy reference gearbox: 11 particles over a period of 4 hours. 


\section{Gearbox: Oil Debris Monitoring by K1 K3 [17]}
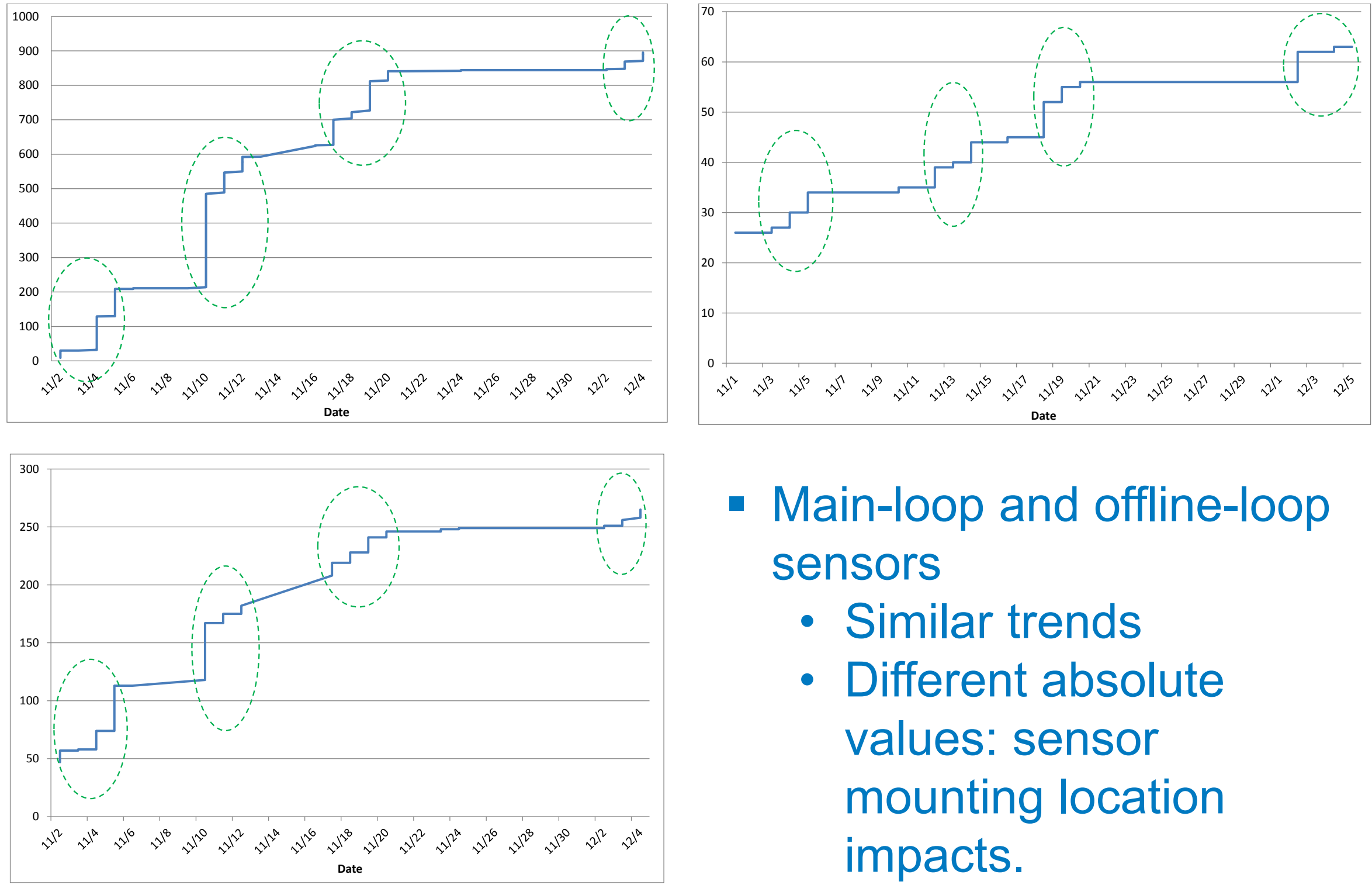

- Main-loop and offline-loop sensors

- Similar trends

- Different absolute values: sensor mounting location impacts. 


\section{Gearbox: Oil Cleanliness by K4 [17]}

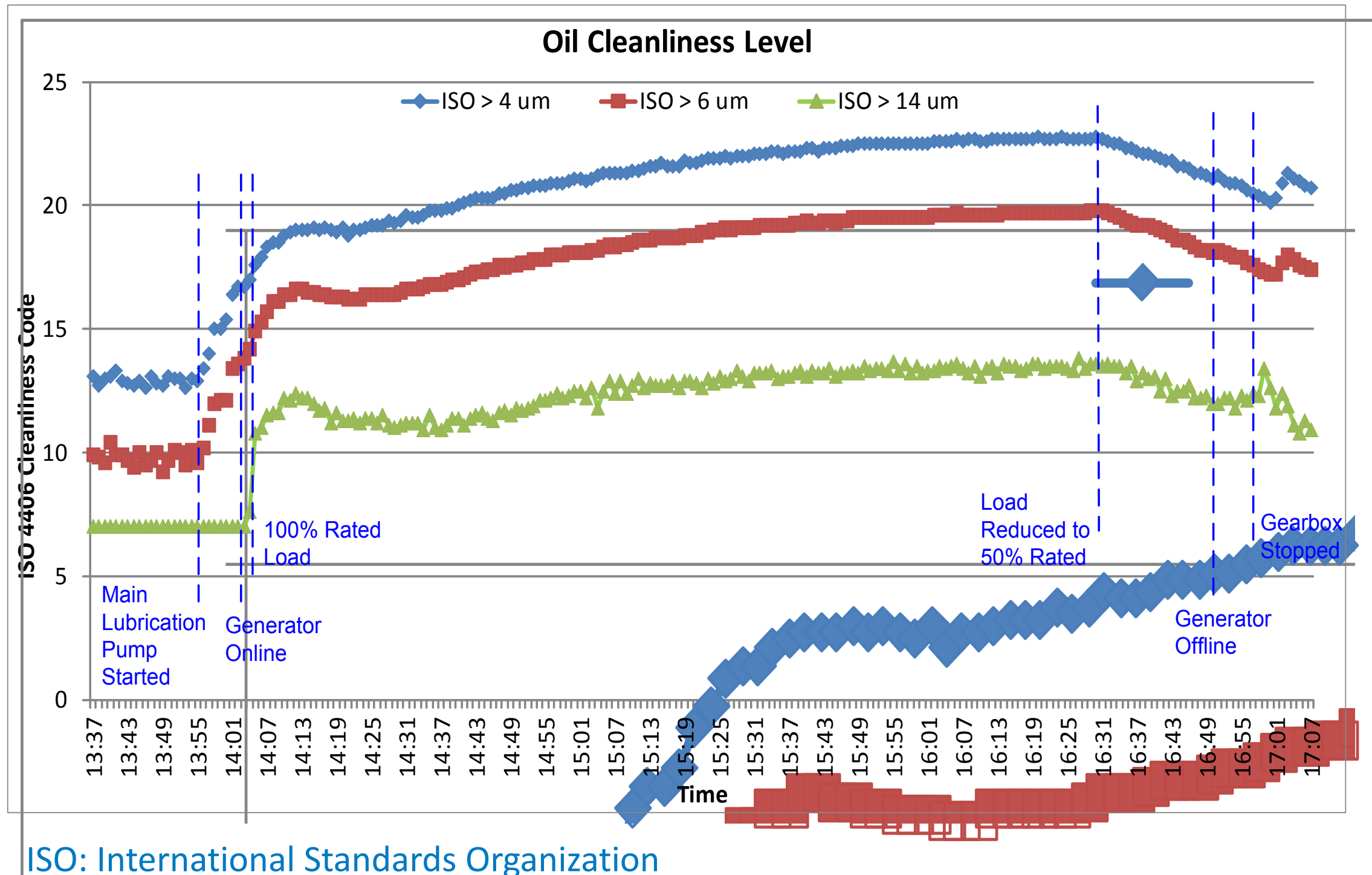




\section{Gearbox: Oil Cleanliness by K4 (Cont.) [17]}

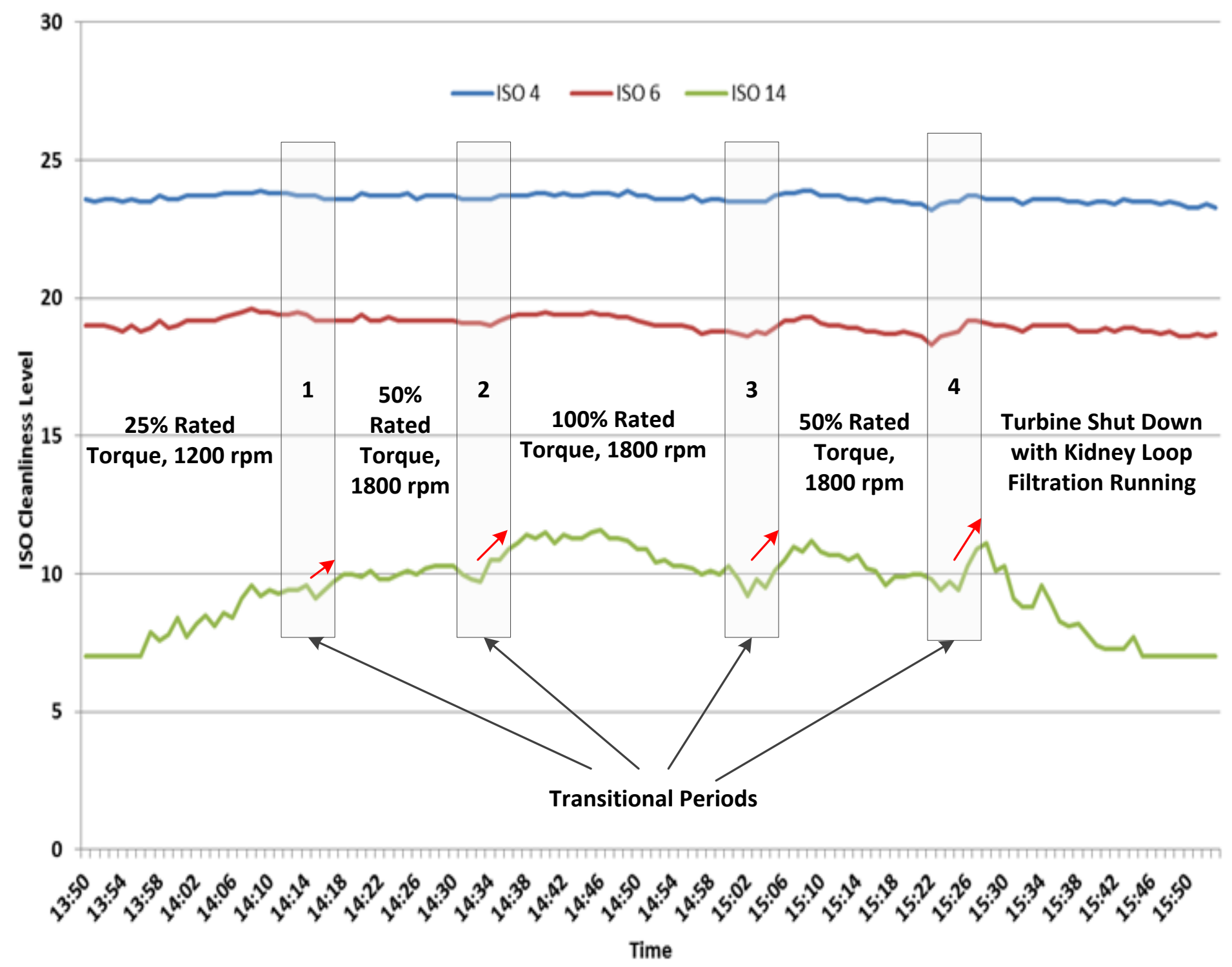




\section{Gearbox: Oil Sample Analysis [17]}

- Results: dynamometer test of the reference gearbox

- Particle counts: important to identify particle types.

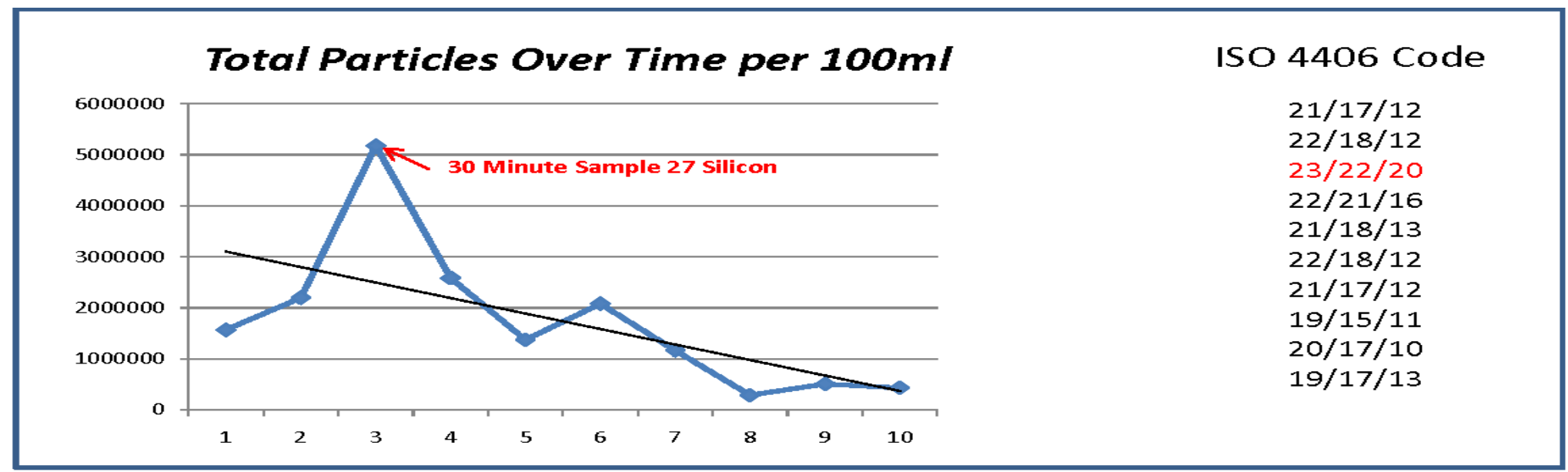

- Element identification

\begin{tabular}{l|} 
Metals \\
Iron ppm \\
Aluminum ppm \\
Chromium ppm \\
Copper ppm \\
Lead ppm \\
Tin ppm \\
Nickel ppm \\
Silver ppm \\
Silicon ppm \\
Sodium ppm \\
Boron ppm \\
Zinc ppm \\
Phosphorus ppm \\
Calcium ppm \\
Magnesium ppm \\
Barium ppm \\
Molybdenum ppm \\
Potassium ppm
\end{tabular}

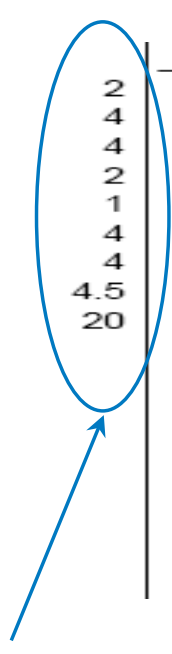

Reference Limits

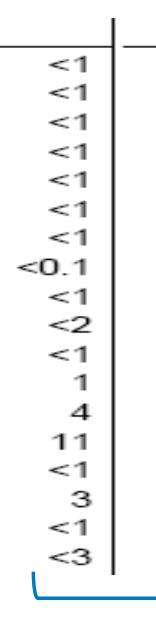

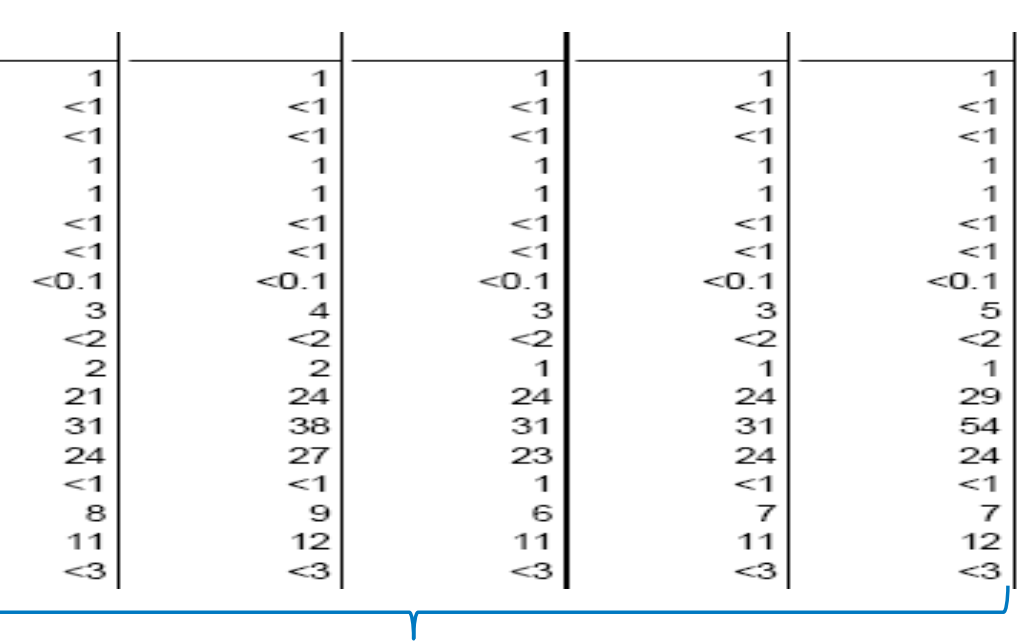

Analysis Results 


\section{Summary: Typical Practices}

- Most performance monitoring data analysis techniques can identify abnormal behaviors and be used for initial screening of potential turbine issues.

- Readily available measured parameters and status codes

- Limited when carrying out a full condition monitoring of wind turbine subsystems/components.

- Temperature may be used as a reliable indicator for the condition monitoring of main bearings, generator bearings, or gearbox high-speed stage bearings, but may not provide enough lead time to save the monitored component.

- Most condition monitoring data analysis techniques can help pinpoint specific subsystems/components with faults and enable prognostics and health management. 


\section{Summary: Typical Practices (Cont.)}

- Vibration analysis appears to be the most widely investigated and reported technique. It can monitor the health of most drivetrain, and even turbine, subsystems/components.

- May have challenges with low-speed-stage subsystems/components.

- Results from counting oil debris are easier to interpret and provide unique information on gearboxes (typically the only oil-lubricated subsystem in a wind turbine) because damaged gearboxes release particles at increased rates.

- Effective for monitoring gearbox component damage, and similar trends can be obtained between main and kidney filtration loops.

- Not effective for pinpointing damage locations. 


\section{Summary: Typical Practices (Cont.)}

- Measurements of oil cleanliness levels can be used to monitor and control the run-in of wind turbine gearboxes.

- Transient events appear more damaging.

- When obtaining particle counts through oil-sample analysis, attention should be given to identifying particle types.

- Periodic oil-sample analysis may help pinpoint failed components and root-causes. 


\section{Summary: Typical Practices (Cont.)}

- Dedicated condition monitoring systems require additional investment for instrumentation and resources for data analysis or results interpretation.

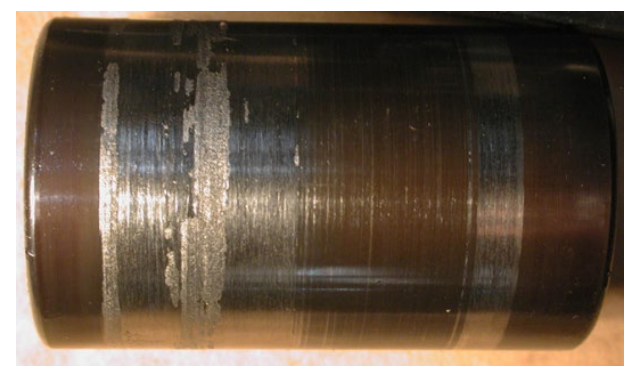

Scuffing

- Given the diverse and complex failure modes seen in wind turbine drivetrains, an integration approach is recommended.

- Start with an initial digest of SCADA data and then fuse several dedicated techniques by considering their advantages and disadvantages.

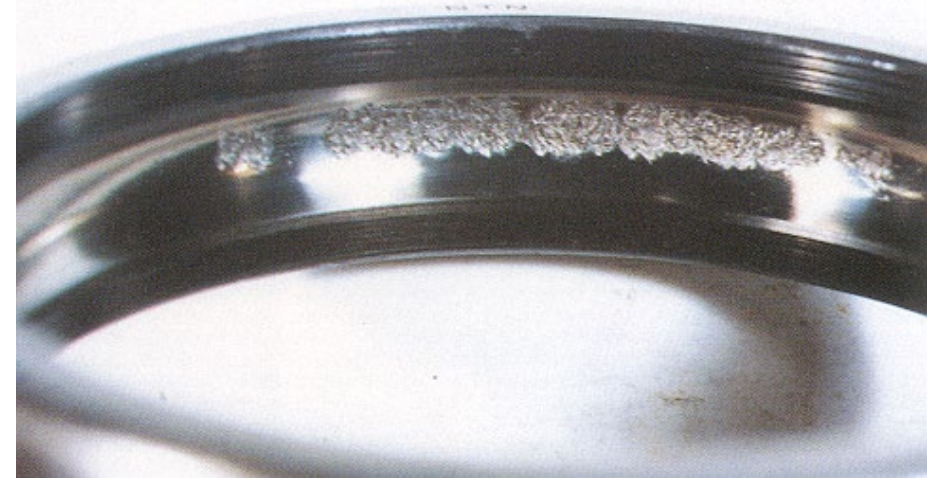

Spalling

Photo Credits: Andy Milburn, Milburn Engineering (top); and Ryan Evans, Timken (bottom) 


\section{R\&D Activities}

- Efforts not widely practiced by the wind industry.

- All layers within the following prognostics and health management architecture

- Sensing: L1

- Signal Processing and Modeling: L2-L5

- O\&M: L6-L7.

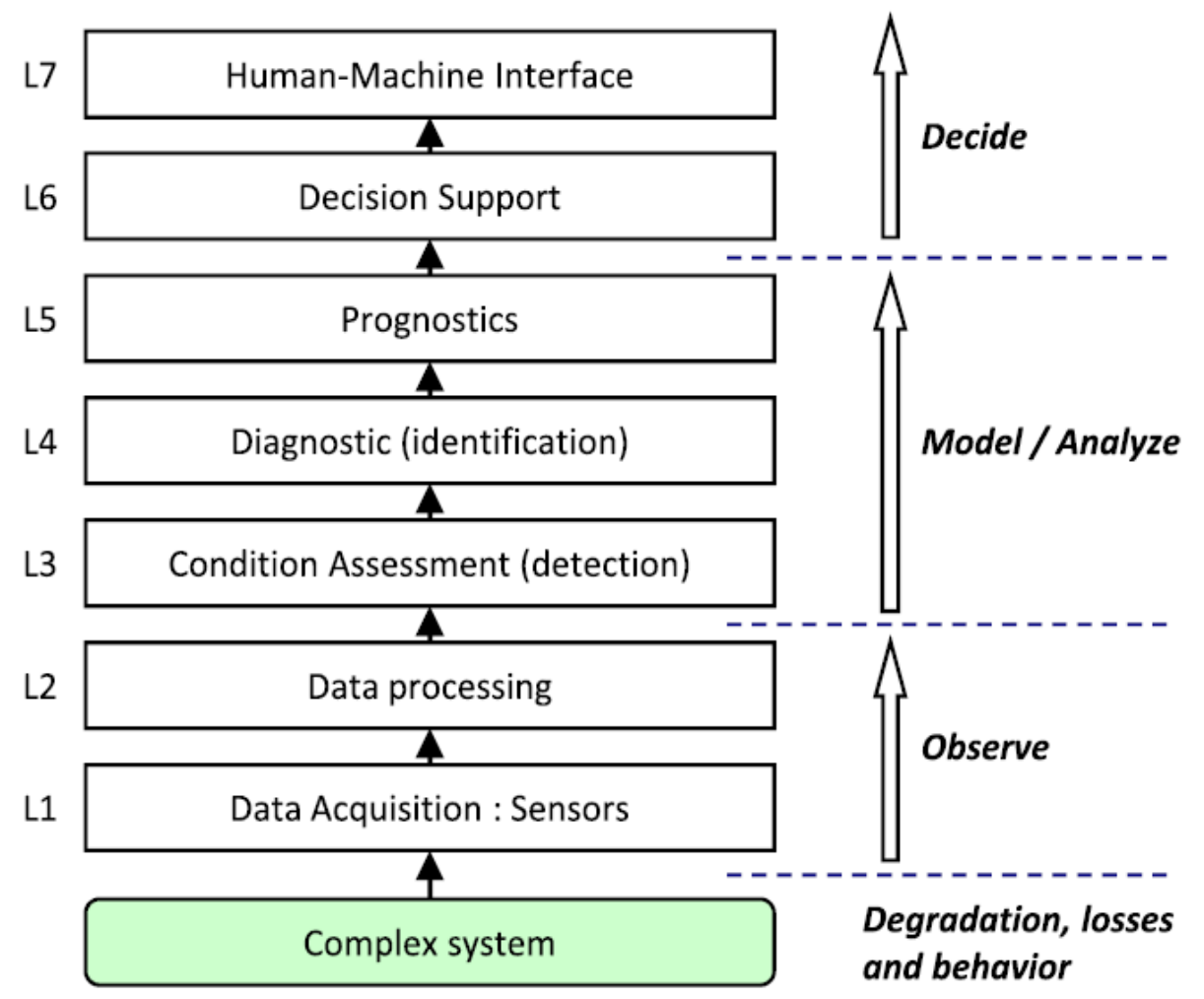

Illustration Source: [9] 


\section{Sensing $[14,18]$}

- Strain measurements: external nondestructive

\section{5}

- Shock-pulse method: low-speed components

- Filter-element analysis: complementary to oil-sample analysis

- Electric-signature analysis: only verified at test rig or small-scale wind turbines

- Oil-condition measurements: oil property deterioration over age; long-term study is needed. 


\section{Signal Processing and Modeling}

- Time-Frequency Analysis [5]

- Wavelet transform and Wigner-Ville distribution: nonstationary not nonlinear

- Empirical mode decomposition: nonstationary and nonlinear, desired frequency range identification not flexible.

- Data-Driven Modeling [5, 19]

- Neural network: efficient but hard to train

- Genetic programming: mathematically simulate complex problem but hard to understand physical meaning

- Regression analysis based on normal conditions and discrepancy evaluations: SCADA data mining and modeling not meeting complete prognostics and health management requirements.

- Physics-Based Modeling [20]

- Bearing life model and miner's rule: component-specific may become complex for a turbine. 


\section{O\&M}

- Not many activities for land-based wind plants $[21,22]$

- Partially observed Markov decision process for optimal repair strategies of wind turbines to minimize cost under stochastic weather conditions

- Cost-benefit-risk model for evaluation of wait-to-maintain option with assumed remaining useful life and a prognostic indication.

- Active for offshore wind plants [23, 24]

- Time domain Monte-Carlo simulation to find out the most costeffective approach to allocate O\&M resources considering environmental conditions, transportation systems, failures, and repairs

- Bayesian theory for optimal planning of inspections and maintenance based on a single wind turbine and a single component considering inspections, repairs, and loss of production. 


\section{R\&D Activities}

- Sensing

- Need to justify the added cost to be widely accepted by the industry

- Has potential especially for those complementary to the popular vibration and oil analysis such as shock-pulse, filter-element, and electric-signature analysis.

\section{- Signal Processing and Modeling}

- Academically very attractive but oftentimes computationally expensive and hard to implement in the field

- Modeling work faces validation challenges as it normally needs longterm data collection, which is very difficult within the wind industry.

- O\&M

- Less attractive to owners and operators of land-based wind power plants, as they may face parts and technician availability challenges

- More attractive to offshore wind plant owners and operators because of the high value proposition mainly caused by even less accessibility and additional logistics and scheduling complexities. 


\section{Concluding Remarks}

- Summary

- Future R\&D Opportunities

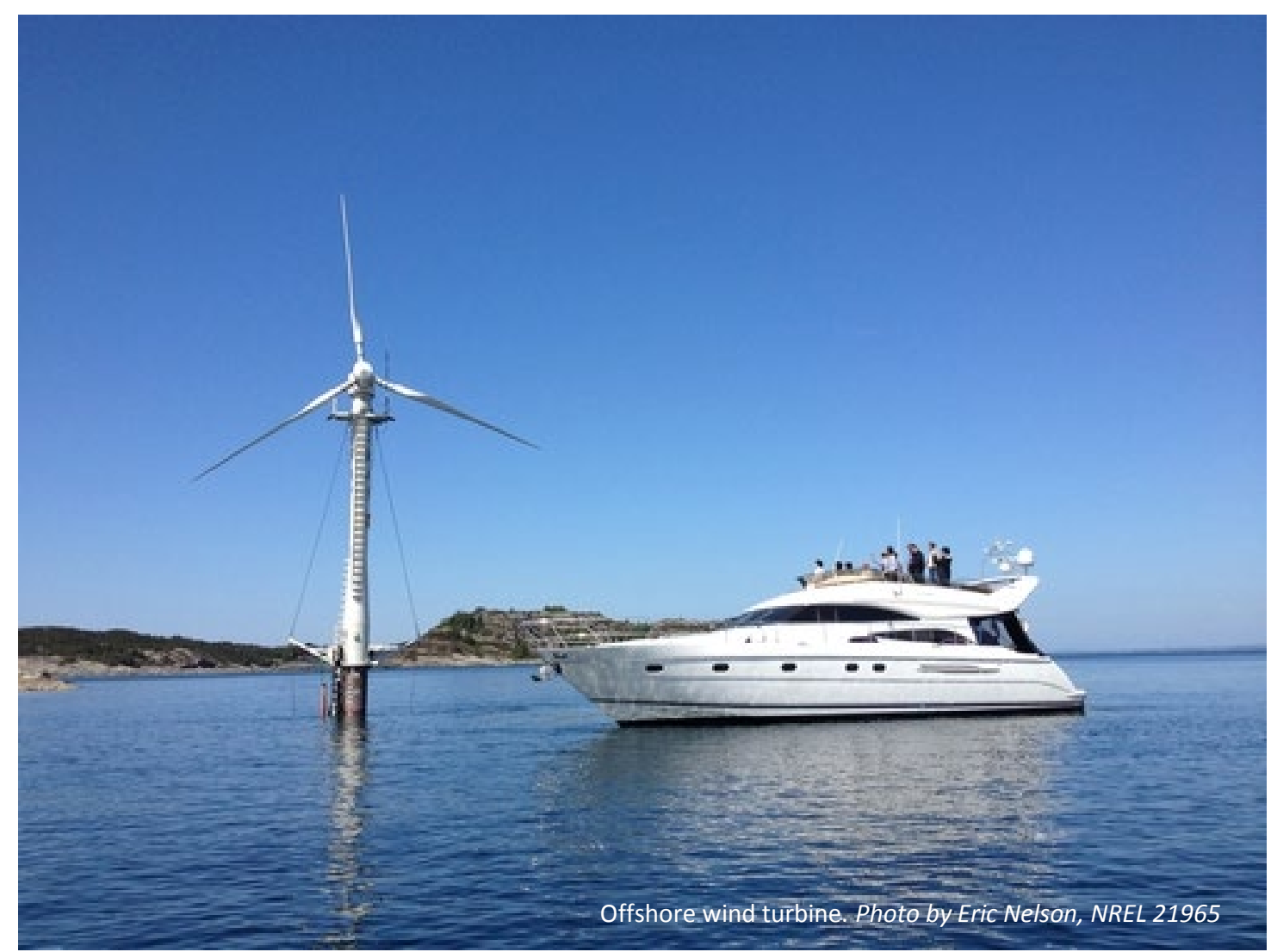




\section{Summary}

- Prognostics and health management in the wind industry has been focusing on the first four layers, and gaps with the other few layers need to be filled to maximize the benefits of prognostics and health management to wind.

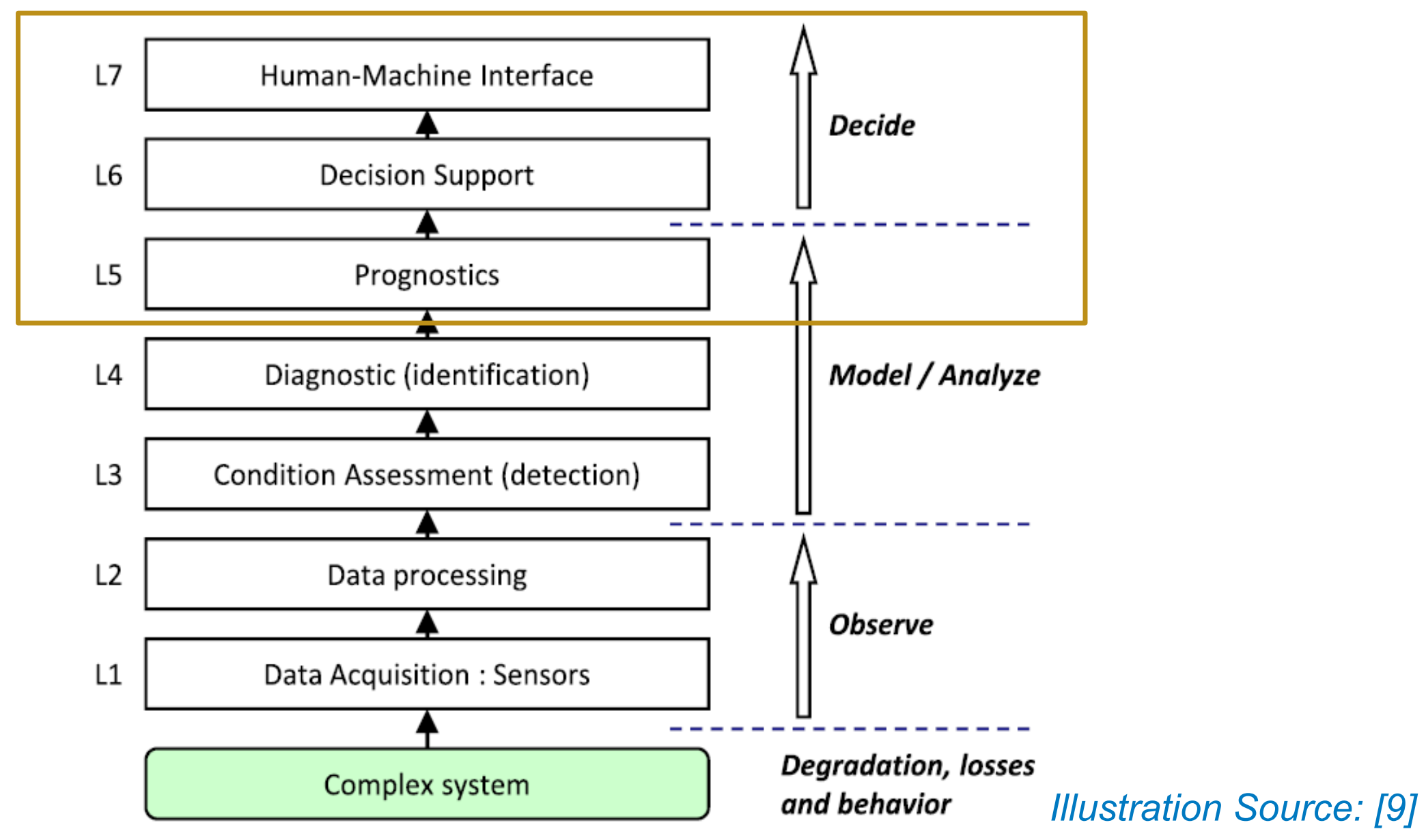




\section{Future R\&D Opportunities}

- O\&M

- Fusion of various data streams to optimize O\&M practices, reduce loads, and extend life of turbine subsystems/components

- Automate data interpretation to deliver actionable maintenance recommendations.

- Signal Processing and Modeling

- Research on improved use of SCADA data

- Improve accuracy and reliability of diagnostic decisions, including level of severity evaluation

- Develop reliable and accurate prognostic techniques to enable remaining useful life estimation of turbine components/subsystems. 


\section{Future R\&D Opportunities}

- Sensing

- Complementary or superior to solutions currently adopted by the wind industry

- New technologies targeting next critical subsystem/component in wind turbines

- Uncertainty representation and interpretation, quantification, propagation, and management [25]

- Perspective shift from individual turbine to entire plant

- Research plant-level or fleet-wide condition monitoring and asset management technologies

- Big data analytics and Internet of Things

- Field application feasibility study and cost effectiveness justification for any prognostics and health management solutions to impact the industry in a big way.

\section{Challenging, yet rewarding.}




\section{References}

1. Global Wind Energy Council. (2015). Global Wind Report Annual Market Update 2014. [Online] http://www.gwec.net/wpcontent/uploads/2015/03/GWEC Global Wind 2014 Report LR.pdf.

2. Y. Feng and P. Tavner, "Introduction to Wind Turbines and Their Reliability \& Availability" (paper presented at the European Wind Energy Conference, Warsaw, Poland, April 20-23, 2010).

3. P. Tavner, F. Spinato, G. J. W. van Bussel, and E. Koutoulakos, "Reliability of Different Wind Turbine Concepts with Relevance to Offshore Application" (paper presented at the European Wind Energy Conference, Brussels, Belgium, March 31-April 3, 2008).

4. Groupe Reaction Inc. and K. Chamberlain, WEU Onshore Asset Optimization \& Reliability Benchmarking Report 2015.

5. W. Than, P. J. Tavner, C. J. Crabtree, Y. Feng, and Y. Qiu, "Wind Turbine Condition Monitoring: Technical and Commercial Challenges," Wind Energy 17(5) (2014): 673-693.

6. R. Meadows, "Offshore Wind O\&M Challenges" (paper presented at the Wind Turbine Condition Monitoring Workshop, Broomfield, Colorado, September 19-21, 2011).

7. "Global Wind Turbine O\&M Market Likely to Reach $\$ 20.6 B n$ by 2023 , Report Says." Posted December 7, 2015, http://www.offshorewind.biz/2015/12/07/global-wind-turbine-om-marketlikely-to-reach-20-6bn-by-2023-reportsays/?utm source=emark\&utm medium=email\&utm campaign=daily-update-offshore-wind2015-12-08\&uid=9484.

8. Z. S. Chen, Y. M. Yang, and H. Zheng, "A Technical Framework and Roadmap of Embedded Diagnostics and Prognostics for Complex Mechanical Systems in Prognostics and Health Management Systems," IEEE Transactions on Reliability 61(2) (2012): 314-322. 


\section{References}

9. M. Jouin, R. Gouriveau, D. Hissel, M. C. Péra, and N. Zerhouni, "Prognostics and Health Management of PEMFC - State of the Art and Remaining Challenges, " International Journal of Hydrogen Energy 38(35) (2013): 15307-15317.

10. J. Coble, P. Ramuhalli, L. Bond, J. W. Hines, and B. Upadhyaya. "A Review of Prognostics and Health Management Applications in Nuclear Power Plants," International Journal of Prognostics and Health Management, ISSN 2153-2648, 6(016) (2015): http://www.phmsociety.org/sites/phmsociety.org/files/phm submission/2015/ijphm 15 016.pdf.

11. K. S. Wang, V. S. Sharma, and Z. Y. Zhang, "SCADA Data based Condition Monitoring of Wind Turbines," Advances in Manufacturing, 2 (2014): 61-69.

12. F. Castellani, A. Garinei, L. Terzi, D. Astolfi, M. Moretti, and A. Lombardi, "A New Data Mining Approach for Power Performance Verification of An Onshore Wind Farm," Diagnostyka, 14(4) (2013): 35-42.

13. F. P. García Márquez, A. M. Tobias, J. M. Pinar Pérez, and M. Papaelias, "Condition Monitoring of Wind Turbines: Techniques and Methods," Renewable Energy, 46 (October 2012): 169-178.

14. S. Sheng and W. Yang, "Wind Turbine Drivetrain Condition Monitoring - An Overview" (paper presented at the American Society of Mechanical Engineers Turbo Expo, San Antonio, Texas, June 3-7, 2013).

15. C. Walleck, "Predictive Analytics in Wind Power" (paper presented at the Wind Turbine Condition Monitoring Workshop, Broomfield, Colorado, September 19-21, 2011).

16. S. Sheng, "Investigation of Various Condition Monitoring Techniques Based on a Damaged Wind Turbine Gearbox" (paper presented at the 8th International Workshop on Structural Health Monitoring Proceedings, Stanford, California, September 13-15, 2011). 


\section{References}

17. S. Sheng, "Monitoring of Wind Turbine Gearbox Condition through Oil and Wear Debris Analysis: A Fullscale Testing Perspective," Tribology Transactions (forthcoming), doi: 10.1080/10402004.2015.1055621.

18. P. Tchakoua, R. Wamkeue, M. Ouhrouche, F. Slaoui-Hasnaoui, T. Tameghe, and G. Ekemb, "Wind Turbine Condition Monitoring: State-of-the-Art Review, New Trends, and Future Challenges," Energies, 7(4) (2014): 2595.

19. S. Sheng, "Improving Component Reliability Through Performance and Condition Monitoring Data Analysis" (paper presented at Wind Farm Data Management \& Analysis North America, Houston, Texas, March 25-26, 2015).

20. C. S. Gray and S. J. Watson, "Physics of Failure Approach to Wind Turbine Condition Based Maintenance," Wind Energy, 13(5) (2010): 395-405.

21. B. Eunshin, L. Ntaimo, and D. Yu, "Optimal Maintenance Strategies for Wind Turbine Systems Under Stochastic Weather Conditions," IEEE Transactions on Reliability, 59(2) (2010): 393-404.

22. G. Haddad, P. A. Sandborn, and M. G. Pecht, "Using Maintenance Options to Maximize the Benefits of Prognostics for Wind Farms," Wind Energy, 17(5) (2014): 775-791.

23. Y. Dalgic, I. Lazakis, I. Dinwoodie, D. McMillan, and M. Revie, "Advanced Logistics Planning for Offshore Wind Farm Operation and Maintenance Activities," Ocean Engineering, 101 (2015): 211-226.

24. J. J. Nielsen and J. D. Sørensen, "On Risk-based Operation and Maintenance of Offshore Wind Turbine Components," Reliability Engineering \& System Safety, 96(1) (2011): 218-229.

25. S. Sankararaman and K. Goebel, "Uncertainty in Prognostics and Systems Health Management," International Journal of Prognostics and Health Management, 6(010) (2015), https://www.phmsociety.org/sites/phmsociety.org/files/phm_submission/2015/ijphm_15_010.pdf. 


\section{Thanks for Your Attention!}

Special thanks go to the U.S. Department of Energy, the research partners working with NREL!

This work was funded by the U.S. Department of Energy under Contract No. DE-AC36$08 G 028308$ with the National Renewable Energy Laboratory. Funding for the work was provided by the DOE Office of Energy Efficiency and Renewable Energy, Wind and Water Power Technologies Office. The author is solely responsible for any omissions or errors contained herein.

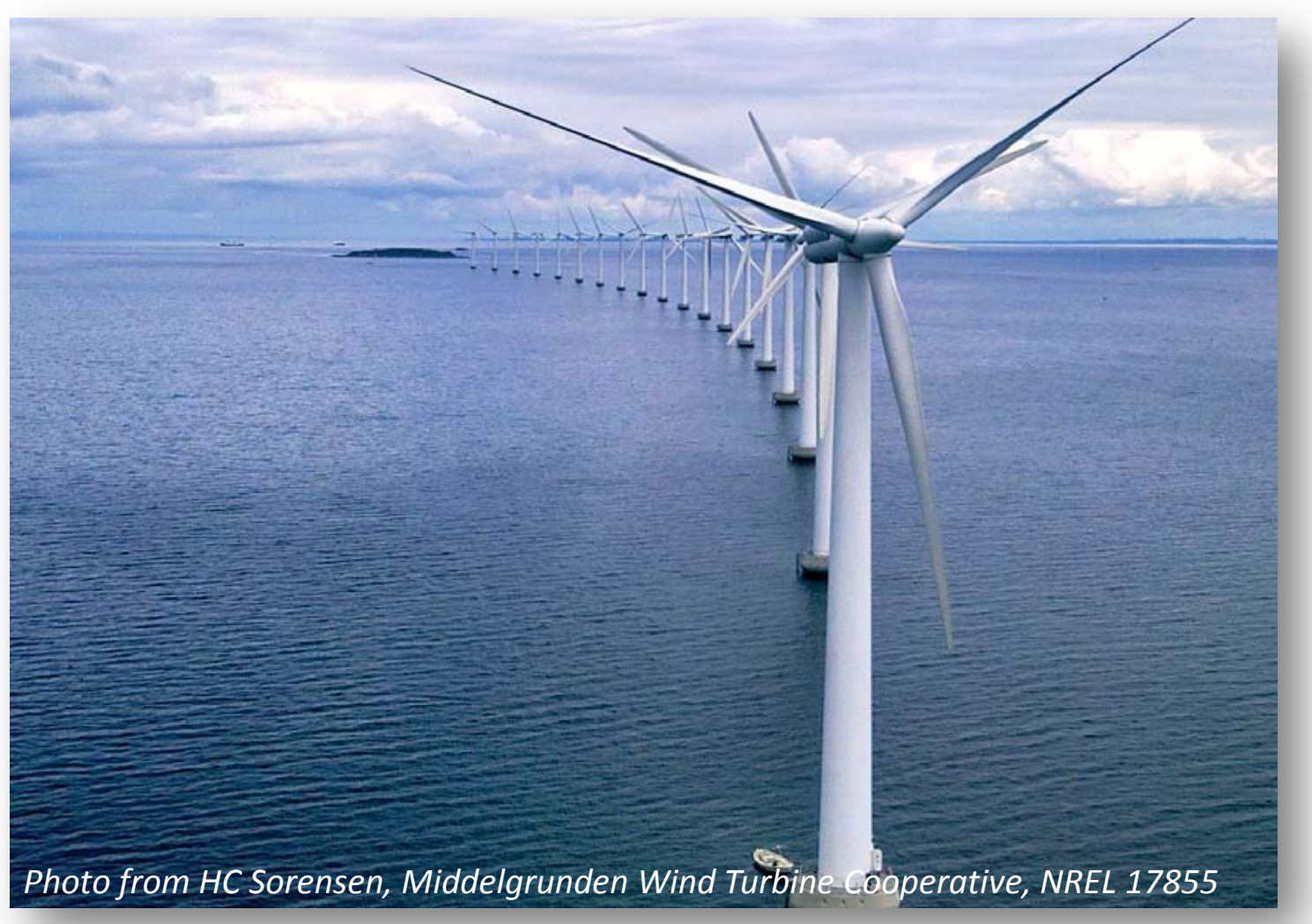

shuangwen.sheng@nrel.gov

303-384-7106 